Tse, P. \& Hyland, K. (2010). Claiming a territory: relative clauses in journal descriptions. Journal of Pragmatics. 42: 1880-1889.

\title{
Claiming a Territory: Relative Clauses in Journal Descriptions
}

\author{
Polly Tse \\ $\&$ \\ Ken Hyland \\ The Hong Kong University of \\ Institute of Education \\ Science \& Technology \\ University of London
}

\begin{abstract}
The study of evaluative features of language has been a productive source of insights into academic discourse in recent years, revealing the ways that persuasion is achieved in a range of genres. This research, however, has largely focused on word-level features, such as stance adverbials and evaluative adjectives (e.g. Hunston \& Thompson, 2000), with the evaluative potential of clause-level resources under-explored. Nor has research had much to tell us about the more peripheral genres of the academy which are concerned with the distribution, rather than the production, of knowledge. In this paper we address both these issues by examining the role of the relative clause construction in a corpus of journal descriptions, the texts which define and endorse the goals and position of a journal. Our analysis of 200 journal descriptions in four contrasting disciplines reveals that relative clauses have an important, and perhaps surprising, role to play in this genre, functioning pragmatically as an evaluative and persuasive tool to promote academic journals.
\end{abstract}

The last two decades have seen an enormous interest in the study of professional written academic genres such as research articles (Ruiying \& Allison, 2003; Swales, 2004), abstracts (Hyland, 2004; Kaplan et al, 1994), and book reviews (Tse \& Hyland, $2006 \& 2008$ ). While these studies have enhanced our understanding of the construction of disciplinary scholarship, surprisingly little has been said about the genres concerned with the distribution, rather than the production, of knowledge. These 'carrier genres', however, play an indispensable role in the mechanisms of delivering and promoting learning, from establishing 
the expectations of editors in journal instructions to contributors (Gianonni, 1991) to endorsing a monograph in back-cover blurbs (Gesuato, 2007; Gea Valor \& Inigo Ros, 2009). This paper sets out to contribute to this growing body of research by examining the journal description (JD), a missive that accompanies every academic journal, but which until recently has managed to escape the scrutiny of text analysts.

The academic journal is the most influential and celebrated medium for disseminating knowledge, for no finding, discovery, or insight has any validity until it has gained peer approval through publication in a research journal. In fact, the manufacture of knowledge is now a massive industry with the online database SCOPUS, for example, listing 16,000 peer reviewed journals and adding another 600 or so new publications each year. To remain competitive in this crowded market, it is strategically important for a journal to delineate itself from others and to establish an independent brand. To justify its existence and persuade readers of its worth, every journal has to "establish as unique an identity as possible" (Miller \& Harris, 2004:74). To this end, the journal description, which appears on the publishers' webpage and inside the front cover of every print periodical, serves an essential role. It functions to construct a journal's character and demarcate an academic territory through an official statement of its aims, scope and readership.

Despite its self-proclaimed 'descriptive' character, however, the journal description is actually a highly persuasive and evaluatively-charged genre as it employs various linguistics resources to define, occupy and defend a unique scholarly niche. Hyland \& Tse (2009), for example, found that the journal description helps position the journal favourably in the academic community through a series of identifiable rhetorical moves peppered with positive lexis. An unexplored area, however, is the role of clause level resources in the goal of favourably positioning the journal. 
This paper sets out to address this gap by examining the role of the relative clause in these evaluations. We decided to focus on the relative clause as its key function is to 'identify people and things, or to give more information about them' (Swan, 1996:473) and this seemed a likely useful resource in the journal description genre in individualizing a given journal and constructing its unique standing.

The following gives a taste of a typical journal description and the potential functions relative clauses can serve in this genre (relative clauses underlined):

(1) BBA is an international journal that is one of the most comprehensive journals in biological sciences covering biochemistry, biophysics, molecular biology, cell biology, genomics, bioinformatics, metabolomics, proteomics and systems biology. BBA is comprised of 9 sections that continually evolve to keep pace with the rapid developments in biological sciences. The papers published should provide mechanistic insight into important questions in biology. The international Editorial Board is typically composed of two Executive Editors for each section and a truly international board of Editors that are committed to provide authoritative and timely reviews of manuscripts. BBA currently comprises the following sections: Bioenergetics, Biomembranes, Gene Regulatory Mechanisms, General Subjects, Molecular and Cell Biology of Lipids, Molecular Cell Research, Proteins and Proteomics, Molecular Basis of Disease and Reviews on Cancer. Impact factor of this journal 2006: 2.024

(Biology)

The example illustrates the way relative clauses help create a favourable image of the journal through the provision of detailed characterization. Here these clauses focus readers on the journal's impressive comprehensiveness, the cutting-edge nature of its articles, and the devotion of its editorial board by manipulating the descriptive space which the relative clauses enable. Of particular interest is the frequency by which these clauses are used to provide evaluative information, suggesting that a re-examination of the traditional characterization of the relative clause as simply defining or adding optional information might be worthwhile. 
In the rest of this paper, we discuss the relative clause structure in more detail and examine the functions it serves in a corpus of 200 journal descriptions by exploring the entities that they modify and the types of modifications these involve. In so doing, we argue that just as the journal description is never merely descriptive, the meaning potential of relative clauses tends to be stretched to perform various functions beyond its typical role of simply identifying or supplementing already supplied information.

\section{The English Relative Clause}

The relative clause is "a clause which modifies a noun or noun phrase" (Richards et al, 1992: 393) and is typically introduced by a relative pronoun such as that, which, who, when, or where. It is a type of noun post-modifying structure similar to an adjective in function but differing from it in that it opens up more space for detailed descriptions. Relative clauses are often characterized in textbooks and grammar guides by their role in giving additional information about the head nouns so that readers/ listeners are able to identify them more easily or recover more information about them. Thomson \& Martinet (1993), for example, follow this two-part functional definition. They recognize defining relative clauses which, "describe the preceding noun so as to distinguish it from other nouns of the same class" (ibid: 81) (as in example 2), and non-defining relative clauses which "are placed after nouns which are definite already (as in 3), thus they do not define the noun, but merely add something to it by giving some more information about it" (ibid: 85):

(2) The noise that he made woke everybody up.

(Defining)

(3) My neighbor, who is very pessimistic, says there will be no apples this year.

(Non-defining)

(examples from Thomson \& Martinet, 1993)

This distinction is widely recognised in the literature, although the labels may differ, so we find reference to identifying vs non-identifying clauses (e.g. Eastwood, 1999; Swan, 1996) or restrictive 
vs non-restrictive relative clauses (e.g. Quirk et al, 1985), with the distinction between them generally seen as relatively unproblematic. The division is considered especially straightforward in writing, where defining/identifying/restrictive relative clauses are said to follow immediately after the nouns that they modify, and non-defining/identifying/restrictive relative clauses are normally separated from it by commas (e.g. Thomson \& Martinet, 1993; Swan, 1996). This convention can be seen in examples (2) and (3) above. Our corpus sample, however, quickly revealed that this binary distinction was not particularly helpful. Not only were the functions of relative clauses often more complex and varied than this, but the presence or absence of a comma was not a reliable discriminator either.

The relative clause from our corpus in (4), for instance, immediately follows the noun "ideas" without a comma, thus suggesting the "defining/identifying/restrictive" status of the clause. The use of the modal may, however, implies quite the opposite as it introduces indefiniteness to the modification and widens the range of possible referents of the noun 'ideas'. It therefore changes how we understand both the sentence and the concept of 'defining, identifying, and restrictive':

(4) It aims at providing a fast means of communication ... and at establishing an informal vehicle for the discussion of ideas that may still be in the formative stage.

$$
\text { (Engineering) }
$$

In fact, the relative clause in (4) seems to be performing rather complicated functions as it serves to highlight inclusiveness (i.e. establishing a vehicle for discussion even if the ideas are in the formative stage), rather than restriction (the journal is only interested in ideas at the formative stage ). Thus, while the relative clause is introducing a specification of the noun, it does this by widening rather than delimiting the referent.

This kind of complexity is often not apparent in considering invented examples and so is seldom discussed in grammars and style guides, while the research literature tends to focus on the 
distribution of syntactic roles and to draw heavily on an arcane nomenclatures of S-relatives, A-relatives and P-relatives (e.g. Fox \& Thompson, 1990; Hardy \& Milton, 1994; Master, 2002). Exploration of the functional roles of relative clauses in academic writing in particular has been largely neglected, with clauses seen as functioning to "simply modify a noun already in the main clause, adding information or precision but not adding to intellectual complexity" (Bazerman, 1984:175).

In fact, emphasis has mainly fallen on the frequency and form of relative clauses, rather than their meanings. Master (2002) and Huckin et al (1986), for example, have explored relative clause reduction in technical writing. They both reported that while the choice between full and reduced relative clauses was affected by factors such as information salience, sentence rhythm, clarity of meanings and economic use of words, the reduced form was more common in the samples of technical writing they examined. Vande Kopple (1998) compared the distribution and form of relative clauses used in Spectroscopic articles published in the 1980s with those in earlier papers. His study suggested a stylistic shift towards a manner which reflects structures, categories and hierarchies, rather than processes, happenings and actions, thus motivating a greater use of tenseless, reduced relative clauses in the later articles.

The point we would most like to stress in this brief overview is that the presentation of relative clauses in grammars and textbooks tend to be oversimplified, reflecting a research literature that has largely focused on surface form and frequency and ignored functions. This neglect means that we have an incomplete description of this structure and can offer only limited help to novice writers. The purpose of the present study is therefore to provide a more comprehensive picture of the functions of relative clauses by analyzing examples from a corpus of journal description. We believe the analysis can help illuminate something of the meaning potential of this structure and also show how it works in a highly promotional and neglected genre. We begin with a description 
of our data and procedures, including the categories that we have developed to capture the complexity in relative clause functions.

\section{Corpus, Decisions and Procedures}

Our corpus of journal descriptions was compiled from 200 refereed journals published by ten leading international academic publishers. Based on the publishers' own categorization, the journals were selected randomly from four broad disciplinary domains: biology, engineering, applied linguistics, and sociology. This selection included only journals published in both print and electronic formats and deliberately avoided specialisms which seemed too esoteric or fringe so we could better capture the ways more mainstream journals represent themselves to their communities. We collected descriptions from the journal websites for convenience, although these are almost always the same as those in the print versions of the periodicals. This produced an electronic corpus of 42,000 words with an average text length of 208 words as shown in table 1. Table 1: Text lengths in words

\begin{tabular}{llllll}
\hline & Biology & Engineering & $\begin{array}{l}\text { Applied } \\
\text { Linguistics }\end{array}$ & Sociology & Overall \\
\hline Total words & 7,324 & 10,720 & 11,627 & 11,978 & 41,649 \\
Average length & 146.5 & 214.4 & 232.5 & 239.5 & 208.25 \\
\hline
\end{tabular}

We decided to include only instances of full relative clauses in our analysis. This was mainly because what is considered to be a reduced relative clause, as opposed to, say a participle or a gerund construction, can be controversial and is not uncontested in the literature (see, e.g. Biber et al, 1999; Hinkel, 2002). We also chose to look at full clauses as reduction tends to be the norm in formal writing (e.g. Biber, 1988). As the examples in (5) show, reduction allows for information to be presented in a more integrated and compact structure:

(5) Journal of Fluid Mechanics is ... essential reading for all those concerned with developments in fluid mechanics. 
The International journal of Thermal Science is a journal devoted to the publication of fundamental studies on the physics of transfer processes.

Expanding these reduced clauses represents a marked option for writers in this genre, and thus the rhetorical advantages offered writers by a full relative clause becomes an interesting research question.

We initially searched the corpus for all the relative pronouns (i.e. that, which, who, whom, whose, where, when, why) and excluded instances where the pronoun was not used to introduce a relative clause. For instance we eliminated all cases where the pronoun acted as a demonstrative pronoun (6) or as a complementizer (7):

(6) Applied Acoustics looks not only at recent developments in the understanding of acoustics but also at ways of exploiting that understanding.

(7) It is not acceptable that papers have a theoretical content alone.

This process left us with 209 full relative clauses. We then, working independently of each other, made repeated passes through the concordance lines examining the relative clauses in their textual contexts to inductively produce a coding scheme of the functions they performed. Having agreed a coding scheme we then, again working separately, looked at each clause and assigned it to a functional category, achieving an inter-rater agreement of $91 \%$. Disagreements - mainly relating to types of modification, were quickly resolved through discussion and a few remaining cases assigned to an 'other' group. We then transferred all examples to WinMax Pro (Kuckartz, 1998), a qualitative text-analysis programme, and sorted and related all cases to each other. This allowed us to further refine our initial judgments and to develop an understanding of the different linguistic and communicative properties of both the entities modified by the relative clause and the type of modification it performed. 


\section{Frequency of Relative Clauses}

The frequency counts suggest the potential importance of relative clause constructions in journal description for there are 209 cases overall, that is, about 5 cases per thousand words and about 1 in every text, even with the limited space that the brief genre offers. Table 2 shows the distribution of these frequencies in the corpus.

Table 2: Frequency of full relative clauses in the corpus

\begin{tabular}{lllll}
\hline Discipline & Total Words & Number & $\begin{array}{l}\text { Per 1,000 } \\
\text { words }\end{array}$ & Per Text \\
\hline Biology & 7,324 & 47 & 6.4 & 0.9 \\
Engineering & 10,720 & 54 & 5.0 & 1.1 \\
Applied Linguistics & 11,627 & 63 & 5.4 & 1.3 \\
Sociology & 11,978 & 45 & 3.8 & 0.9 \\
Total & 41,649 & 209 & 5.0 & 1.0 \\
\hline
\end{tabular}

The table indicates that although the disciplinary sub-corpora contained a similar number of relative clauses per text, there were notable differences in the density of cases per 1,000 words between disciplines. The science texts contained $22 \%$ more relative clauses per 1,000 words than the social sciences texts - a finding that intriguingly contrasts with Master's (2002) results which showed that Biology and Engineering were among the fields with the lowest percentage of full relative clauses in research reports. The higher proportion of full relative clauses in the sciences in our study perhaps suggests something of the specific rhetorical purposes of the journal description. This purpose requires a very precise delineation and characterization of journals in the highly competitive business of scientific publishing.

\section{A Classification of Relative Clauses}

A classification scheme was inductively developed as described above based on what we see as the two major aspects of relative clause construction: the entity modified by the clause and the type of modification it expresses. These were further divided into more specific sub-categories to reflect 
the functions that relative clauses serve in journal descriptions. These are summarized in Table 3

and discussed below.

Table 3: Classification of relative clause functions

\begin{tabular}{|c|c|c|c|}
\hline Aspects & \multicolumn{2}{|l|}{ Sub-categories } & Examples \\
\hline Modified & \multirow{2}{*}{\multicolumn{2}{|c|}{$\begin{array}{l}\text { a) audience: the target users of the } \\
\text { journal }\end{array}$}} & "It presents a common forum for all scientists who \\
\hline \multirow[t]{8}{*}{ Entity } & & & take an explicitly organism oriented ...” \\
\hline & \multirow{2}{*}{\multicolumn{2}{|c|}{$\begin{array}{l}\text { b) the journal: the publication or its } \\
\text { contents }\end{array}$}} & $\begin{array}{l}\text { "Research in Engineering Design is an } \\
\text { international journal that publishes research..."; }\end{array}$ \\
\hline & & & $\begin{array}{l}\text { "The journal ... creates a fund of technological } \\
\text { information that can be..." }\end{array}$ \\
\hline & \multirow{2}{*}{\multicolumn{2}{|c|}{$\begin{array}{l}\text { c) themes: the objects, issues and } \\
\text { approaches of study }\end{array}$}} & "The scope extends further to all those aspects of \\
\hline & & & $\begin{array}{l}\text { life which either favor or hinder ..."; "Studies on } \\
\text { species which are more primitive..." }\end{array}$ \\
\hline & \multirow{2}{*}{\multicolumn{2}{|c|}{ d) formats: the text types represented }} & "The journal welcomes articles and discussions \\
\hline & & & that identify aspects of ESP needing development" \\
\hline & \multicolumn{2}{|l|}{ e) others } & $\begin{array}{l}\text { "Articles should be written in a manner that is } \\
\text { intelligible..." }\end{array}$ \\
\hline \multirow{13}{*}{$\begin{array}{l}\text { Type of } \\
\text { Modification }\end{array}$} & \multirow[t]{4}{*}{ a) Scope: } & \multirow[t]{3}{*}{ i) delimiting } & "InJAL publishes articles that focus on the \\
\hline & & & mediation between expertise about language and \\
\hline & & & experience of language." \\
\hline & & ii) expanding & $\begin{array}{l}\text { "Manuscripts that address all fields of } \\
\text { applications of acoustics....are welcome." }\end{array}$ \\
\hline & \multirow[t]{4}{*}{ b) Clarity: } & i) elaboration & $\begin{array}{l}\text { “... state-of-the art articles, which keep them up to } \\
\text { date with key areas of research and development } \\
\text { and provide essential bibliographies" }\end{array}$ \\
\hline & & \multirow[t]{3}{*}{ ii) exemplification } & $\begin{array}{l}\text { "The journal covers the whole spectrum of } \\
\text { mechanical engineering, which includes, but is not }\end{array}$ \\
\hline & & & limited to, Materials and Design Engineering, \\
\hline & & & Production Engineering, and Fusion Technology." \\
\hline & \multirow[t]{5}{*}{ c) Evaluation \& } & \multirow[t]{2}{*}{ i) scope } & $\begin{array}{l}\text { "The journal is also dedicated to...fruitful } \\
\text { exchanges that will stimulate future research on }\end{array}$ \\
\hline & & & issues of social inequality" \\
\hline & & \multirow[t]{3}{*}{ ii) clarity } & "BBA is comprised of 9 sections that continually \\
\hline & & & evolve to keep pace with the rapid developments in \\
\hline & & & biological sciences" \\
\hline
\end{tabular}


The Modified Entity refers to what is being modified, i.e. the noun or noun phrase qualified by the relative clause and here we identify five sub-categories: a) audience, i.e. the targeted users of the journal, including its intended readers and potential contributors; $b$ ) the journal itself and the sections that it carries; c) research themes, or the topics of investigation and focus areas; d) the formats represented in the journal, including the genres and types of contributions; and e) others, which refer to the handful of cases where the modified entity did not fall into any of our other categories, such as an abstract entity, an historical event, or an institution.

The Type of Modification refers to the functions expressed in the relative clause itself with regard to the noun or noun phrase it modifies. It is important to be clear here that, unlike previous studies, we are not concerned about whether a relative clause is identifying or not because as Halliday (1994) points out, it is the definitive article the at the beginning of the noun phrase that carries the identifying function, not the relative clause. Consequently, we can only talk about the identifying potential of the elements in the relative clause and this potential is available to all types of clause modification.

We identified three broad categories of modification: a) The first concerns the scope of the noun's reference and the extent to which the clause acts to either specify this scope more specifically through restriction or expand it by encompassing other candidates. b) Clarity is where the clause is used to offer a clearer understanding of the modified entity by explanatory comment. This may involve i) elaboration where additional details are provided or ii) exemplification, which offers an instance of a general category. c) Evaluation expresses the writer's attitude or judgment towards the modified entity. This category almost always co-occurs with other categories. This is because "evaluation appears parasitic on other resources and to be somewhat dispersed across a range of structural options shared with non-evaluative functions" (Hunston \& 
Thompson, 2000:74). Thus we see evaluation with reference to the scope of the entity (both specifying and expanding) and elaboration in our corpus. In other words, the relative clause is contributing to the meanings of the modified entity both in terms of its objective property as well as the value and judgment ascribed to it.

\section{Modified entities: what writers comment on}

While all four disciplines employed relative clauses to refer to each of the categories we identified, over half of all cases concerned the formats accepted by the journal (Table 4).

Table 4: Modified entities by disciplines (percent)

\begin{tabular}{llllll}
\hline & Biology & Engineering & App Ling & Sociology & Totals \\
\hline Formats-represented & 51.5 & 57.4 & 58.7 & 51.5 & $\mathbf{5 5 . 0}$ \\
Research themes & 19.1 & 20.4 & 9.5 & 15.6 & $\mathbf{1 5 . 8}$ \\
The journal & 10.6 & 13.0 & 15.9 & 8.9 & $\mathbf{1 2 . 4}$ \\
Audience & 12.8 & 3.7 & 4.8 & 17.8 & $\mathbf{9 . 1}$ \\
Others & 6.4 & 5.6 & 11.1 & 6.7 & $\mathbf{7 . 7}$ \\
Total & $\mathbf{1 0 0 . 0}$ & $\mathbf{1 0 0 . 0}$ & $\mathbf{1 0 0 . 0}$ & $\mathbf{1 0 0 . 0}$ & $\mathbf{1 0 0 . 0}$ \\
\hline
\end{tabular}

The overwhelming focus on this area in all disciplines is perhaps not surprising as one of the key functions of the genre is to inform readers of the types of contribution accepted by the journal (Hyland \& Tse, 2009). Relative clauses therefore notify possible authors of permissible genre formats and features of the things it publishes, generally either functioning to clarify the advantages of such formats (8) or specify more closely what is valued in them (9):

(8) SYNTAX features short articles which facilitate a fast review process.

FEBS letters provides an international forum for mini-reviews, hypotheses and research letters that merit urgent publication.

(9) The scope includes theoretical, numerical and experimental studies that contribute to the fundamental understanding and/or application of fluid phenomena

The editors are therefore particularly interested in papers that uncover the processes by which social networks emerge, evolve and have consequences for other aspects of behaviour. 
...stimulating articles which manage to combine maximum readability with scholarly standards.

We can see here that the writers of journal descriptions are not only keen to provide information to authors by specifying the kinds of submissions they welcome, but also to promote the journal by highlighting how submissions might benefit them. The relative clause offers an economical means of briefly elaborating on genre formats to sell the journal to its public, pointing to the priorities researchers might consider when weighing up the merits of competing journals as venues for their research and establishing the standing of the journal to potential readers. Here then, we often find reference to how a format can facilitate speed of publication or something of the quality expected when submitting.

Following a considerable distance behind formats in frequency, research themes constitute the second most common item modified by a relative clause. This is especially prominent in the harder science fields of Engineering and Biology where research themes comprised 20\% of all cases:

(10) Particular importance will be attached to aspects of innovation in mechatronics design philosophy which illustrate ....

The journal will no longer consider manuscripts just describing the cloning, sequencing and expression patterns of gene sequences that have been identified...

(Bio)

The topics covered by journals is particularly important in the natural sciences where the sheer volume of knowledge and its rapid expansion oblige both journals and individuals to establish their own niches of expertise. Research in these fields is more typically characterized by linearity and well-defined and agreed upon problems (Toulmin, 1972) so that new knowledge is generated from what is known and each new finding inexorably contributes to the eventual solution of the issue under study. 
Becher and Trowler (2001) refer to these as 'urban' features where a relatively small number of problems is pursued by a substantial number of scientists, whether in response to fashion, funding, or paradigmatic breakthrough. In contrast to more 'rural' disciplines where research is spread out over a broad range of topics with long term solutions, urban specialisms tend to cluster around a few salient topics and encourage relatively quick, short range solutions to a series of questions. There tends to be considerable competition in these areas and a precise delineation of interest. This high degree of specialism not only means that research success involves an ability to make precise contributions to a highly delimited field, but encourages journals to promote ever-more restricted sub-topics so that scientists can pin-point their submissions and their reading more exactly.

In contrast, this kind of specification of research themes seems far less important in applied linguistics, where only $9.5 \%$ of cases functioned in this way. Instead, there are slightly more cases of relative clauses being used to refer to the publication itself or to sections of the publication, a feature which is also prominent in the engineering descriptions:

(11) English For Specific Purposes is an international peer-reviewed journal that welcomes submissions from across the world.

SYNTAX contains a reviewed Open Forum section which debates ......

Strain is an international journal that contains contributions...

This strategy is less apparent in the journal descriptions in Sociology, however, perhaps because it is a discipline which relies more heavily on endorsements from prominent scholars as a promotional strategy than self-proclamations (Hyland \& Tse, 2009). Sociology does, however, employ relative clauses more than the other fields in our sample to say more about its readership, identifying more precisely who might be interested in the content of the journal: 
(12) All articles...should also be accessible to a wide readership which includes policymakers, academic staff and students within and beyond the UK. (Soc)

.... provides a unique blend of research, policy and practice from leading authors for an audience which includes academics, practitioners and policy makers.

(Soc)

Finally, there were a few cases in the corpus, largely in texts taken from applied linguistics journals, which did not fall neatly into the other categories. The fact that the relative frequency of these heterogeneous items was unusually high here indicates something of the particular emphasis the field attaches to writing style (13) and to the continuing emergence of the discipline as a relative newcomer to the academic world (14):

(13) Written in language that new readers will find accessible, articles... (AL )

(14) With the directions that are now being taken in language issues $(\mathrm{AL})$

Another important factor that ties them together as a field is...... a tradition that distinguishes itself from the study of ....

In the next section, we turn to describe the kinds of qualification expressed in the relative clause structures and the relation between modified entities and functions across disciplines.

\section{Types of modification: qualifying the entities}

Grammar guides and textbooks describe relative clauses as mainly used for restricting or elaborating information, or what we have called modifying scope and clarity, and half of all cases in our corpus perform the first of these. Table 5 shows the distribution of modifying functions across the four disciplines in our journal description texts. 
Table 5: Types of modification by disciplines (percent)

\begin{tabular}{llllll}
\hline & Biology & Engineering & App Ling & Sociology & Totals \\
\hline Scope & $\mathbf{4 4 . 7}$ & $\mathbf{4 8 . 1}$ & $\mathbf{5 0 . 8}$ & $\mathbf{5 5 . 6}$ & $\mathbf{4 9 . 8}$ \\
Specification & 44.7 & 40.7 & 47.6 & 53.3 & $\mathbf{4 6 . 4}$ \\
Expansion & 0 & 7.4 & 3.2 & 2.2 & $\mathbf{3 . 3}$ \\
Clarity & $\mathbf{8 . 5}$ & $\mathbf{2 0 . 4}$ & $\mathbf{2 0 . 6}$ & $\mathbf{8 . 9}$ & $\mathbf{1 5 . 3}$ \\
Elaboration & 6.4 & 14.8 & 20.6 & 6.7 & $\mathbf{1 2 . 9}$ \\
Exemplification & 2.1 & 5.6 & 0 & 2.2 & $\mathbf{2 . 4}$ \\
Evaluation and & $\mathbf{4 6 . 8}$ & $\mathbf{3 1 . 5}$ & $\mathbf{2 8 . 6}$ & $\mathbf{3 5 . 6}$ & $\mathbf{3 4 . 9}$ \\
Scope (Specifying) & 27.7 & 29.6 & 14.3 & 24.4 & $\mathbf{2 3 . 4}$ \\
Clarity (Elaborating) & 19.1 & 1.9 & 14.3 & 11.1 & $\mathbf{1 1 . 5}$ \\
Total & $\mathbf{1 0 0}$ & $\mathbf{1 0 0}$ & $\mathbf{1 0 0}$ & $\mathbf{1 0 0}$ & $\mathbf{1 0 0}$ \\
\hline
\end{tabular}

Modification in JDs mainly concerns the specification of the scope of the message, narrowing the range of interpretations which can be put on it. They function to either define a subset for a term or add a further specification to something that is already presented as explicit:

(15) Environmental Science and Policy promotes communication among government, business and industry, academia, and non-governmental organizations who are instrumental in the solution of environmental problems.

(Bio )

The scope includes all aspects of physics, chemistry, material sciences.... which relate directly to the subject of wear and friction...

(Eng )

Discourse \& Communication specifically addresses readers in any field of communication who are interested in qualitative, discourse analytical approaches.

(AL )

In contrast, examples which concern the expansion of scope were negligible, accounting for only $3 \%$ of all the relative clause use. So, while some journals may aspire to be comprehensive in their coverage and appeal, they generally prefer to carve out a specialist niche in terms of an audience and area of study.

The links between the function of relative clauses and the topics they modified in the different disciplines can be seen in Table 6. 
Table 6: Relationship between Modified Entities and Types of Modification (\%)

\begin{tabular}{|c|c|c|c|c|c|c|c|c|}
\hline & \multicolumn{4}{|c|}{ Biology } & \multicolumn{4}{|c|}{ Engineering } \\
\hline & Scope & Clarity & Evaluation & Total & Scope & Clarity & Evaluation & Total \\
\hline Works Rep & 41.7 & 4.2 & 54.2 & 100 & 61.3 & 0.0 & 38.7 & 100 \\
\hline Res Themes & 66.7 & 11.1 & 22.2 & 100 & 45.5 & 27.3 & 27.3 & 100 \\
\hline Journal & 0 & 20.0 & 80.0 & 100 & 0 & 71.4 & 28.6 & 100 \\
\hline Audience & 83.3 & 0.0 & 16.7 & 100 & 100 & 0.0 & 0.0 & 100 \\
\hline Others & 0.0 & 33.3 & 66.7 & 100 & 0 & 100 & 0.0 & 100 \\
\hline \multirow[t]{3}{*}{ All } & 44.7 & 8.5 & 46.8 & 100 & 48.1 & 20.4 & 31.5 & 100 \\
\hline & \multicolumn{4}{|c|}{ Applied Linguistics } & \multicolumn{4}{|c|}{ Sociology } \\
\hline & Scope & Clarity & Evaluation & Total & Scope & Clarity & Evaluation & Total \\
\hline Works Rep & 54.1 & 8.1 & 37.8 & 100 & 47.8 & 0.0 & 52.2 & 100 \\
\hline Res Themes & 83.3 & 16.7 & 0.0 & 100 & 100 & 0.0 & 0.0 & 100 \\
\hline Journal & 20.0 & 50.0 & 30.0 & 100 & 0.0 & 25.0 & 75.0 & 100 \\
\hline Audience & 100 & 0.0 & 0.0 & 100 & 75.0 & 12.5 & 12.5 & 100 \\
\hline Others & 28.6 & 57.1 & 14.3 & 100 & 33.3 & 66.7 & 0.0 & 100 \\
\hline Total & 50.8 & 20.6 & 28.6 & 100 & 55.6 & 8.9 & 35.6 & 100 \\
\hline
\end{tabular}

A closer examination of the correlations between the functions of relative clause and the entities they modified shows that research themes and audience were almost exclusively qualified by the specification of scope. Table 6 shows that this is particularly marked in the case of sociology JDs, where all research themes were presented in this way (16), and applied linguistics and engineering, where all audience were (17):

(16) who share an interest in the study of the empirical structure of social relations and association that may be expressed in network form. (Soc)

Papers on topics which clearly have broad implications and interrelationships based on the experiences of the developing or developed world will be considered.

(Soc)

(17) Discourse and Communication specifically addresses readers in any field of communication who are interested in qualitative, discourse analytical approaches... 
Audience: Practicing engineers both in industry and academia who are involved in the design and/or manufacture of products using computer controlled mechanisms or electromechanical systems.

(Eng)

Overwhelmingly, however, relative clauses in almost all disciplines were employed to more closely define the areas of research, methodologies or application which the journal aspired to align itself:

(18) Experimental Thermal and Fluid Science provides a forum for research emphasizing experimental work that enhances basic understanding of heat transfer, thermodynamics and fluid mechanics, and their applications.

System prefers its contributors to provide articles which have a sound theoretical base with a visible practical application which can be generalized.

....and the use of biomolecular materials to synthesize artificial systems that capture essential principles of natural biological information processing.

(Bio)

While Table 6 shows that adjustments to the scope of information is the most prominent function of relative clauses in journal descriptions, it is by no means the only one. Writers also modified their messages for clarity, particularly in engineering and applied linguistics (Table 5), and they did this principally by employing elaborations. We can now see from Table 6 that this was mainly to modify statements about the Journal itself and about unclassified entities. Most unclassified entities are abstract, and so naturally require more clarification:

(19) The link areas form a circle that encompasses the fundamental nature of biological information processing.

More importantly though, these two disciplines tend to use relative clauses to give additional information about the journal itself, its sections or its goals:

(20) The Modern Language Journal also offers Perspectives, a section that appears in issues 2 and $4 \ldots$

The Journal aims to encourage ... and in so doing creates a fund of technological information that can be used to solve related problems. 
The Journal of English for Academic Purposes provides a forum for the dissemination of information and views which enables practitioners of and researchers in EAP to keep current with developments in their field.

These frequencies, however, are relatively low compared with the numbers used to delimit the scope and to offer an evaluation of the material presented.

\section{Evaluation: shaping reader attitudes}

The role of evaluation is a more significant aspect of relative clause use, as the figures in Tables 5 and 6 suggest. In referring to the potential audience and writers for the journal, for example, positive opinions about the readership are often added to the delimitating meanings carried by the specification of the scope. This occurred so frequently, in fact, that we decided to include this as a separate category, adding evaluation to a specification of scope. So from this function we not only learn something of the target audience of the journal, but also that they represent an elite of inquiring and well rounded academics, qualities which naturally reflect well on the journal itself:

(21) This rigorously peer-reviewed Journal has contained a wide selection of materials ... by contributors who are not only authorities in their field, but can also write with vigor, clarity, and occasionally with humour.

Computational Biology and Chemistry should be read by academics, students and professionals, who are interested in state-of-the-art computational life sciences...

For those who would break out of the straitjacket of the methodological imperative Critical Sociology is a necessary and vital forum for alternative ideas. $\quad$ (Soc)

Table 5 shows that the coupling of specification and evaluation is commonplace in the corpus, accounting for over one-third of all cases. To be clear, we suggest that as opposed to a simple specification of scope, instances in this group also involve the writer's evaluative judgments. These are principally realized through adjectival forms (22) and, far less frequently, by verbs and nouns (23): 
(22) Written in language that new readers will find accessible, articles provide insights that seasoned experts will find valuable.

The international Editorial board is typically composed of ... and a truly international board of Editors that are committed to providing authoritative and timely reviews of manuscripts....

(23) The objective of the JSE is to be a forum....that improves our knowledge of the state of the world past and present as well as enriches our causal understanding of the economy.

The journal aims to present papers that provide_conceptual_advance in the relevant field.

In fact, such positive evaluations are characteristic of these texts and are a key feature of what is, in essence, a highly promotional genre. It must be remembered that the journal description seeks to create a 'brand' for the journal, positioning it in the academic firmament and laying claim to a slice of carefully delineated academic territory. This objective means that the journal description is more than simply a statement of aims and scope, as lexical and rhetorical choices both reflect and define what is valued by the target academic community. Relative clauses seem to be one means of attempting to construct a role for the journal in a crowded field of activity and to craft a positive evaluation of its worth and importance to a community of readers.

Evaluation then, while largely neglected in previous studies of relative clauses, appears to be an important part of their function in journal descriptions. Their connection to the specification and clarification of meanings is particularly prominent in biology JDs, in which nearly half of all uses of relative clauses expressed evaluation (Table 5). Table 6 indicates that evaluation in Biology relates especially closely to the modification of the Journal itself, where $80 \%$ of the relative clauses are evaluative, and that sociology closely follows this with a figure of $75 \%$. As can be seen from 
the following examples, evaluation in this area serves to highlight the quality of the journal, either through a greater specification of scope (24) or a clarification of its mission (25):

(24) DNA Research is an internationally peer-reviewed journal which aims at publishing papers of the highest quality in broad aspects of DNA and genomerelated research.

(25) Journal of Socio-Economics is a general economics journal whose calling card is its methodological open-mindedness and a strong commitment to economic rigor and economic or analytical significance as opposed to the simple use of mathematical proofs and statistical significance.

Overall, however, most evaluation in these relative clauses inscribes positive judgments in presenting the range of work represented by the journal. Here the meanings which are expressed move beyond delimiting the kinds of submissions which the journal calls for to provide an evaluation which simultaneously carries an assessment of the journal's quality and status: (26) European Journal of Sociology publishes articles of interdisciplinary scope which represent some of the best writing in the social sciences today.

The editors publish original contributions that will stimulate the intellectual innovation that generates elegant, effective, and economic engineering designs.

In this way, relative clause constructions contribute to a highly positive tenor in these texts, helping to both establish the niche which the journal is intended to occupy and identify its value and relevance to a discerning specialist readership eager to keep abreast of cutting edge developments and theories. The main aim here is to achieve maximum reader buy-in to the goals of the journal, and this is frequently done by specifying that the interests of the journal extend only to those manuscripts which help advance the field in some way:

(27) Cellular Microbiology aims to publish significant contributions on the intersection of microbial and host-cell biology that strongly advance understanding of unique biological processes and mechanisms.

We look for articles that advance the discipline and reach the widest possible audience. 
Through incorporating these lexical choices, then, JD writers use the structure of the relative clause as an economical way of crafting texts which offer a positive evaluation of a product in terms of attributes assumed to be valued by a particular community of readers. The evaluative items which pepper these texts are grounded in, and help to build, a value system thought to be shared with readers and which help promote the journal to them. In this endeavour, relative clauses play an important role by allowing writers to both provide additional information concerning key aspects of the journal to readers and to present this information in a way which appeals to the beliefs and values of a specialist community of scholars.

\section{Conclusions}

Despite its presence on the website and in every issue of every academic periodical, the journal description is something of an unsung genre, largely having avoided the attention of applied linguists and discourse analysts. Its importance, however, lies in its role in positioning the journal in a particular field and in the consciousness of the members of a community: that is, in staking out a specific territory which it can then claim to uniquely occupy. It is, then, a genre touched by the 'promotional culture' (Wernick, 1991) of modern consumerist society which blurs distinctions between fact and evaluation to promote statements in much the same way as products are promoted. In short, journal descriptions support the value and centrality of the journal and advocate a particular definition of disciplinary realities and interests. Perhaps surprisingly, the relative clause construction contributes to this goal.

Relative clauses are used in these texts to modify key aspects of how journals are presented, both providing additional information and, very often, imparting a positive 'spin' to that information. For writers, the structure gives them an efficient and economical means of conveying material succinctly in a genre tightly constrained by word limits. Readers want to decide relatively quickly about whether this is an appropriate venue for their research or source of information for their 
interests, and relative clause structure is an efficient means of packaging this data. In exploring how they work in this way, we have found the traditional defining/non-defining dichotomy to be unhelpful and have suggested a possible classification based on functional-rhetorical principles which more effectively accounts for their frequency and function in this genre.

The relative clause, by delineating a specialized area of expertise and claiming a central significance in this area, therefore does more than simply narrowing down the meaning of a noun or distinguishing a member from a larger set. Its traditional description which links it to defining and non-defining functions, has led applied linguists to overlook the evaluative potential of this structure and its role in creating an attitude in the reader to the thing discussed.

While it remains to be seen how useful this categorization may be when applied in other contexts, it seems to be a fairly robust way of describing how relative clauses function pragmatically as an evaluative and persuasive tool to promote academic journals. It also occurs to us that there may be value in taking these observations into the classroom where advanced students might benefit from seeing how relative clauses can not only convey factual information, but also assist them to incorporate judgment and comments appropriately in their academic writing. We would also suggest that the journal description itself might be a good starting place to explore this structure with them. Not only does the evaluative role of relative clauses occur frequently here, but the texts are of manageable length for analysis, present information about academic values, journal interests and expectations, and convey something of the hidden promotional elements of academic texts which might benefit junior researchers. 


\section{References}

Bazerman, Charles (1984). The writing of scientific non-fiction . Pre/Text, 5(1), 39-74.

Becher, Tony and Trowler, Paul (2001). Academic Tribes and Territories: Intellectual Inquiry and the Cultures of Disciplines. Milton Keynes: SRHE and Open University Press.

Biber, Douglas (1988). Variation across speech and writing. Cambridge: CUP.

Biber, Douglas, Johansson, Stig, Leech, Geoffrey, Conrad, Susan and Finegan, Edward (1999). Longman Grammar of Spoken and Written English. London: Longman.

Eastwood, John (1999). Oxford Practice Grammar. Oxford: Oxford University Press.

Fox, Barbara \& Thompson, Sandra (1990). A discourse explanation of the grammar of relative clause in English conversation. Language, 66(2), 297-316.

Gea Valor, Maria-Lluisa \& Inigo Ros, Marta (2009). On the Dynamic Nature of Genres: A Diachronic Study of Blurbs. in Hyland. K. \& Diani, G. (eds.)

Gesuato Sara (2007) 'Evaluation in Back-cover Blurbs', in M. Dossena and A. H. Jucker (eds) '(R)evolutions in Evaluation', special issue of Textus XX(1), 83-101.

Giannoni, Davide (2001). ‘The Disciplined Scholar: Deontic Modality in Editors' Instructions to Contributors', in M. Gotti \& M. Dossena (eds), Modality in Specialized Texts, Bern: Peter Lang, 311-340.

Halliday, M. A. K. (1994). An Introduction to Functional Grammar (2nd edn). London: Edward Arnold.

Hardy, Donald \& Milton, Karen (1994). The distribution and function of relative clauses in literature. Pragmatics and Language Learning. Monograph Series, Vol 5. University of Illinois,: Urbana, IL. pp 247-265.

Hinkel, Eli (2002). Second Language Writers' Text. Mahwah, NJ: Lawrence Erlbaum. 
Huckin, Thomas, Curtin, Elizabeth \& Graham, Debra (1986) Prescriptive linguistics and plain English: the case of "whiz-deletions". Visible Language, XX(2), 174-187.

Hunston, Susan \& Thompson, Geoff (Eds), (2000). Evaluation in text, Oxford University Press: Oxford

Hyland, Ken (2004). Disciplinary discourses: Social interactions in academic writing. Ann Arbor, MI: University of Michigan Press.

Hyland. Ken \& Diani, Giulianna (eds.) (2009) Academic evaluation: review genres in university settings. Basingstoke, Palgrave.

Hyland, Ken \& Tse, Polly (2009) 'The leading journal in its field': Evaluation in Journal Descriptions. Discourse Studies.

Kaplan, R., Cantor, S., Hagstrom, C., Lia, D., Shiotani, Y. and Zimmerman, C. B. (1994). ‘On abstract writing'. TEXT, 14(3), 401-26.

Kuckartz, U. (1998) WinMAX: Scientific text analysis for the social sciences. Thousand Oaks, CA: Sage.

Master, Peter (2002) 'Relative clause reduction in technical research articles', in E. Hinkel \& S. Fotos (eds), New Perspectives on Grammar Teaching in Second Language Classroom.,Mahwah, N.J.: Lawrence Erlbaum Assoc. Inc, 201-231.

Miller, Case \& Harris, Julianna (2004). Scholarly Journal Publication: Conflicting Agendas for Scholars, Publishers, and Institutions. Journal of Scholarly Publishing, January, 73-91.

Richards, Jack, Platt, John, \& Platt, Heidi (1992). Dictionary of Language Teaching and Applied Linguistics. Harlow: Pearson Education Limited.

Quirk, Randolph, Greenbaum, Sidney, Leech, Geoffrey \& Svartvik, Jan (1985) A Grammar of Contemporary English Language, Harlow, Essex: Longman.

Ruiying, Yang and Allison, Desmond (2003). Research articles in applied linguistics: moving from results to conclusions. English for Specific Purposes, 22(4), 365-85. 
Swales, John (2004). Research Genres. Cambridge: CUP

Swan, Michael (1996). Practical English Usage. Oxford: Oxford University Press.

Thomson, A.J. \& Martinet, A.V. (1993). A Practical English Grammar. Oxford: Oxford University Press.

Toulmin, Stephen (1972). Human Understanding, 1, Oxford: Clarendon Press.

Tse, Polly \& Hyland, Ken (2008). 'Robot Kung fu': gender and the performance of a professional identity. Journal of Pragmatics. 40 (7): 1232-1248.

Tse, Polly \& Hyland, Ken (2006). 'So what is the problem this book addresses?' Interactions in book reviews. Text and Talk. 27. 767-790.

Vande Kopple, William (1998). Relative clauses in Spectroscopic articles in the Physical Review, beginnings and 1980. Written Communication, 15(2), 170-202. 